\title{
Arbuscular Mycorrhizal Fungi (AMF) as Buffer for Heavy Metals Phytoextraction by Cucurbita maxima Duch. Grown on Crude Oil Contaminated Soil
}

\author{
O.G. Okon ${ }^{1, a^{*}}$, J.E. Okon ${ }^{2, b}$, G.D.O. Eneh ${ }^{3}$ \\ ${ }^{1}$ Department of Botany and Ecological Studies, University of Uyo, Uyo, Nigeria \\ ${ }^{2}$ Biological Sciences Department, Akwa Ibom State University, Ikot Akpaden, Nigeria \\ ${ }^{3}$ Department of Science Technology, Akwa Ibom State Polytechnic, Ikot Osurua, Nigeria \\ aokonokongodwin@yahoo.com, bokjunior4zeeb@gmail.com
}

\begin{abstract}
Keywords: Cadmium, Copper, Chromium, Crude oil, Cucurbita maxima, heavy metals, Lead, Rhizophagus irregularis, Zinc.
\end{abstract}

\begin{abstract}
This study evaluated the influence of Arbuscular Mycorrhizal (Rhizophagus irregularis) fungi inoculation (M) on the growth of Cucurbita maxima and as a buffer against phytoextraction of selected heavy metals $(\mathrm{HM})(\mathrm{Zn}, \mathrm{Cu}, \mathrm{Cr}, \mathrm{Cd}$ and $\mathrm{Pb}$ ) from a soil polluted with crude oil (C). The experiment was set up using four soil treatments, in triplicates $\mathrm{C}+\mathrm{M}-\mathrm{C}+\mathrm{M}+, \mathrm{C}-\mathrm{M}+$ and $\mathrm{C}-\mathrm{M}-$ (control without crude oil and inoculum). The shoot length, petiole length, number of nodes, leaf area and percentage germination of $C$. maxima were significantly $(\mathrm{p}=0.05)$ reduced in uninoculated crude oil treatment $(\mathrm{C}+\mathrm{M}-)$, unpolluted mycorrhizal inoculated treatments $(\mathrm{C}-\mathrm{M}+)$ showed remarkable response in growth parameters above the control $(\mathrm{C}-\mathrm{M}-)$, while the polluted and inoculated treatment $(\mathrm{C}+\mathrm{M}+)$ showed significant $(\mathrm{p}=0.05)$ increase in growth parameters when compared to the polluted uninoculated treatment $(\mathrm{C}+\mathrm{M}-)$. Heavy metals analysis revealed a significant $(\mathrm{p}=0.05)$ difference in the heavy metal accumulation of $C$. maxima. The heavy metals analyzed in this study are present thus in C. maxima; $\mathrm{Zn}>\mathrm{Cu}>\mathrm{Cr}>\mathrm{Pb}>\mathrm{Cd}$. Crude oil polluted uninoculated treatment $(\mathrm{C}+\mathrm{M}-)$ recorded the highest concentrations of heavy metals than crude oil polluted inoculated $(R$. irregularis) treatment $(\mathrm{C}+\mathrm{M}+)$. Mycorrhizal inoculated unpolluted treatment $(\mathrm{C}-\mathrm{M}+)$ and unpolluted uninoculated treatment $(\mathrm{C}-\mathrm{M}-)$ indicated the lowest heavy metal concentrations. Inoculation with $R$. irregularis significantly $(\mathrm{p}=0.05)$ reduced heavy metals uptake by $C$. maxima as observed in this study. Also, the downbeat effect of crude oil on AM Fungi root colonization of $C$. maxima by $R$. irregularis was observed in polluted and inoculated treatment. HM often accumulate in the top soil, therefore, are available for uptake by plants via roots, which is a major entry point of HM that ultimately affects different physiological processes. AM fungi can impinge on the chemical properties of heavy metals in the soil, their absorption by the host plant, and their allocation to different plant parts, affecting plant growth and the bioremediation process, thus making the AM fungi a suitable buffer for mitigating heavy metal stress on C. maxima.
\end{abstract}

\section{Introduction}

Plants and environments are faced with diverse and concurrent types of stresses namely; heavy metals, water logging, heat, salinity, drought, etc. adversely affecting plant growth and the environment. The incidence of different microbes in the soil can be used as a great tool to augment the efficiency of plants and the environment through symbiotic association. Diverse soil microorganisms including arbuscular mycorrhizal (AM) fungi, plant growth-promoting rhizobacteria (PGPR), and endophytic bacteria can positively enhance plant growth under diverse circumstances including stress as well as the properties of the environment $[1,2]$. Anthropogenic actions severely affect our natural habitats. The re-establishment of such stress degraded habitats via sustainable, low input cropping systems with the aim of maximizing yield of crop plants is required for crop productivity. Thus, the integration of the innate roles of these advantageous microbes in sustaining soil productiveness and plant productivity is gaining much more awareness [3]. 
Heavy metals stress is among the most important stresses decreasing the efficiency of plant and the environment [2]. Heavy metals (53 elements) are determined according to their density $\left(>5 \mathrm{~g} / \mathrm{cm}^{3}\right)$ [4]. Some of the heavy metals together with iron (Fe), zinc ( $\left.\mathrm{Zn}\right)$, manganese $(\mathrm{Mn})$, copper $(\mathrm{Cu})$, and nickel $(\mathrm{Ni})$ are essential for plant growth and yield production. Among the main vital functions of such heavy metals in plant are (a) the catabolization of enzymatic and redox activities, (b) the transfer of electron, and (c) as the main part of DNA and RNA metabolism [5]. The other heavy metals like lead $(\mathrm{Pb})$, nickel $(\mathrm{Ni})$, arsenic (As), etc., which are also the sources of contamination, do not have any functions in living organisms. The elevated concentrations of these heavy metals can adversely impinge on the metabolism of plant and soil microbes and hence the food chain and the ecosystem [6]. The sources of heavy metals in the soil are industrialization and urbanization as well as the unsuitable disposal of wastes, which has increased the concentration of heavy metals within the environment [2]. Among such activities the anthropogenic activities including fertilization, the use of herbicides, wastes, and sewage sludge are also among the most important sources of environmental contamination. However, mining is the most important source of trace element in the environment $[2,7]$.

Arbuscular mycorrhizal fungi (AMF), are beneficial root symbionts belonging to the phylum Glomeromycota [8], they are ubiquitous in the environment with little host specificity and extensive geographic allotment which are associated with majority of terrestrial plant species [9]. AMF plays an essential role in the ecosystems steadiness by enhancing the adjustment, growth, and nutrition of plants under unpleasant environmental settings [10,11]. Different mechanisms are used by mycorrhizal fungi to detoxify the adverse effects of heavy metals on the environment and on the growth of the host plant including (a) the production of chelating products, (b) the interaction with the plasma membrane, and (c) the effects of the cell wall components of the fungi and the plant. Such mechanisms can be conducted by the following [2]: (a) Plant growth and the subsequent dilution of heavy metals in the tissues, (b) The production of organic products such as organic acids by plant roots, which prevents the uptake of heavy metals from the rhizosphere by chelating, precipitating, and binding, (c) The selective activity of plasma membrane in the absorption or desorption of heavy metals, (d) The retention and immobilization of heavy metals by the fungal hyphae and plant roots, (e) Chelating heavy metals by metallothioneins in the cytosol of both fungi and the host plant, (f) The activity of specific or non-specific carriers and plasma membrane pores (both fungi and host plant) (g) Heavy metal sequestration by plant and fungi cellular vacuoles, (h) Transfer of heavy metals by the fungal hyphae, (i) The exchange of heavy metals amongst the fungi and the host plant and (j) Active transfer of heavy metals by the specific and non-specific pathways in both fungi and the host plant $[12,13]$.

Cucurbita maxima belongs to the family Cucurbitaceae, they are prostrate or climbing, annuals, they usually reach a length of about 4 meters or further. They possess hispid leaves, which are rounded, about 15 to $30 \mathrm{~cm}$ in diameter, their base has a heart-shape [14]. In many countries in tropical Africa and worldwide, there have been reports of the distribution of C. maxima [15]. It northern Nigeria, C. maxima is cultivated mainly for its fruits, the leaves and fruits are the main aim of $C$. maxima cultivation in southern Nigeria [16]. While the other two species $C$. pepo and $C$. moschata are integral parts of diets of indigenous people of this region [17]. This research was carried out to explore the potential use of arbuscular mycorrhizal fungi (AMF) as a buffer to mitigate phytoextraction of heavy metals by C. maxima from soils contaminated with crude oil.

\section{Materials and Methods}

\section{Study Area}

This research was carried out in Uyo Local Government Area of Akwa Ibom State, Nigeria. Uyo is a city in South-South Nigeria found between latitude $5.02^{\circ} \mathrm{N}$ and longitude $7.92^{\circ} \mathrm{E}$; it has an average temperature of $25.1-27.8^{\circ} \mathrm{C}$, an annual rainfall of $3300 \mathrm{~mm}$. The plant (Cucurbita maxima) used for this research work was identified by a plant taxonomist in the Department of Botany and Ecological Studies, University of Uyo, Uyo, Nigeria. 


\section{Sources of Crude Oil and Experimental Soil}

The crude oil used for this research was gotten from the Nigerian National Petroleum Commission (NNPC), Aba Road, Port Harcourt-Nigeria. The experimental soil was excavated from the Department of Botany and Ecological Studies Botanic Garden, University of Uyo-Nigeria.

\section{Source of Arbuscular Mycorrhizal (AM) Fungi}

AM Fungi Rhizophagus irregularis (60-65 spores per 5 g) was purchased from International Institute of Tropical Agriculture (IITA) Ibadan-Nigeria.

\section{Pollution and Amendment Treatments}

$10 \mathrm{~kg}$ of the sandy-loam were weighed using a weighing balance (Ohaus Triple Beam 750-SO Weighing Balance). Polluted soils were obtained by mixing thoroughly $10 \mathrm{~kg}$ of sandy-loam with $50 \mathrm{ml}$ of crude oil and left undisturbed for one week, while unpolluted garden soil was used as control.

\section{Propagation and Mycorrhizal Inoculation}

Arbuscular Mycorrhizal fungi Rhizophagus irregularis was propagated on Zea mays planted and grown in a greenhouse for about 16 weeks. The colonized maize roots were used as an inoculum ( $25 \mathrm{~g}$ fresh weight per pot containing approximately 130 spores) was placed in the pot at $15 \mathrm{~cm}$ depth, before planting.

\section{Sterilization of Seeds for Planting}

Seeds of C. maxima were surface sterilized with $0.01 \%$ mercuric chloride solution for 30 seconds, meticulously washed severally with clean distilled water [18]. Five (5) seeds of C. maxima were sown directly in each perforated buckets containing polluted and unpolluted garden soil. On seedling emergence, the plants were thinned to 3 per pot.

\section{Experimental Setup}

This experiment was set up using a complete block design (CBD) having three (3) replicates for C. maxima.

\begin{tabular}{lc}
\hline \multicolumn{1}{c}{ Treatments } & Meaning \\
\hline $\mathrm{C}-\mathrm{M}-$ & - Crude Oil, - Mycorrhiza \\
$\mathrm{C}+\mathrm{M}-$ & + Crude Oil, - Mycorrhiza \\
$\mathrm{C}+\mathrm{M}+$ & + Crude Oil, + Mycorrhiza (Rhizophagus irregularis) \\
$\mathrm{C}-\mathrm{M}+$ & - Crude Oil, + Mycorrhiza (Rhizophagus irregularis) \\
\hline
\end{tabular}

C- (- crude oil), C+ (+ crude oil), M- (- mycorrhiza) M+ (+ mycorrhiza).

\section{Determination of Growth Parameters}

Percentage seedling emergence was calculated as the seeds emerged from the soil five (5) days after sowing. The $\%$ germination for each treatment was calculated using the formula:

$$
\mathrm{n}=\% \text { seedling emergence }=\frac{\text { Number of Emerged Seeds }}{\text { Number of Seeds Sown }} \times \frac{100}{1}
$$

Measurement of growth parameters such as shoot length, root length, petiole length and internode length were taken nine (12) weeks using a measuring tape $(\mathrm{cm})$. Leaf number was counted. Leaf area (LA) was determined using a graph by multiplying the leaf length by leaf width (widest portion) with the correlation co-efficient (r) which was 0.72 .

\section{Heavy Metal Analysis}

The powdered samples were digested with very strong acids, perchloric acid $\left(\mathrm{HCLO}_{4}\right)$ and nitric acid $\left(\mathrm{HNO}_{3}\right)$ and this is called Wet digestion method. The digested samples would be read using Unicam 939 Atomic Absorption Spectrophotometer. 
Wet digestion: $1 \mathrm{~g}$ of the powdered sample was weighed into a digestion flask, $20 \mathrm{ml}$ of nitric acid was added and $10 \mathrm{ml}$ perchloric acid was also added, a drop of concentrated Sulphuric acid added also. The mixture was allowed to stand for 30 minutes and then digested using digestion chamber in the laboratory until the colour turned white. This showed that the samples were digested. They were allowed to cool. Thirty (30) $\mathrm{ml}$ of distilled water were added and were filtered. The filtrate was made up to $50 \mathrm{ml}$ solution with distilled water. The digested solution was stored in a sample bottle ready for the heavy metals analysis using atomic absorption spectrophotometer. The concentrations of Chromium $(\mathrm{Cr})$, Copper $(\mathrm{Cu})$, Lead $(\mathrm{Pb})$, Cadmium $(\mathrm{Cd})$ and $\mathrm{Zinc}(\mathrm{Zn})$ in the powdered samples were determined according to the recommended methods described by the Association of Official Analytical Chemists [19].

\section{Assessment of Arbuscular Mycorrhizal Colonization}

Feeder roots of about 2-4 cm of Cucurbita maxima were collected and fixed in 50\% ethanol and stored for colonization assessment. The fixed roots were rinsed in tap water before clearing in $10 \% \mathrm{KOH} \mathrm{w} / \mathrm{v}$ and autoclaved for about 15 minutes at $121^{\circ} \mathrm{C}$. Cleared roots were collected on a sieve and severally rinsed with tap water before staining. Staining of the plants roots was carried out using a very recently improvised method of staining using ink and vinegar. This staining solution is made up of a $5 \%$ ink watered down in vinegar (5\% acetic acid). Staining with blue writing ink was done by soaking the roots segments in the ink and allowing the stained roots in the staining solution at normal room temperature for a day. The stained plant roots become more visible after destaining soaked roots in 50\% glycerol for about 1 hour [20].

After the stained roots had been cleared of stains, root length was measurement was taken concurrently with mycorrhizal colonization by a gridline intersection procedure independently by viewing slides with a dissecting microscope; where the stained roots are randomly dispersed in a Petri dish plate of about $9 \mathrm{~cm}$ diameter with grid lines. Quantifying intersections was done by scanning alongside these grid lines using a dissecting microscope linking grid lines and roots which are selected as either colonized or non-mycorrhizal. The fraction of the root length that is mycorrhizal and the total root length can then be calculated from a conversion factor resulting from the total length of grid lines and the area of the dish. A minimum of 100 intersections was used to assess the stained root samples; the stained root samples were re-ordered randomly and counted numerous times. Percentage mycorrhizal colonization was calculated using standard methods described by Giovannetti and Mosse [21].

$$
\mathrm{MC}=\frac{\text { Total number of roots infected intersecting gridlines }}{\text { Total number of roots intersecting gridlines }} \times 100
$$

\section{Statistical Analysis}

Data obtained for various growth parameters subjected to pollution and AMF inoculation treatments were analyzed using the Statistical Package for Social Sciences (SPSS) version 20.0 and means alienated with standard error of means. Analysis of variance (ANOVA) was also carried out on data collected for different heavy metal contents of this research. GraphPad Prism analytical software package, version 6 was employed for the reason mentioned above. Duncan's Multiple Range Test was used to separate means at $\mathrm{p}=0.05$.

\section{Results and Discussion}

Duncan Multiple Range comparisons of the means for every treatment showed that there was significant $(\mathrm{p}=0.05)$ difference among treatments analyzed $(\mathrm{C}-\mathrm{M}-, \mathrm{C}+\mathrm{M}-\mathrm{C}+\mathrm{M}+$ and $\mathrm{C}-\mathrm{M}+$ ) (Fig. 1, Fig. 2 and Fig. 3). This indicated a significant difference in the growth parameters (percentage germination, shoot length, petiole length, leaf number, internode length and leaf area of the C. maxima seedlings used in this study (Fig. 1). 

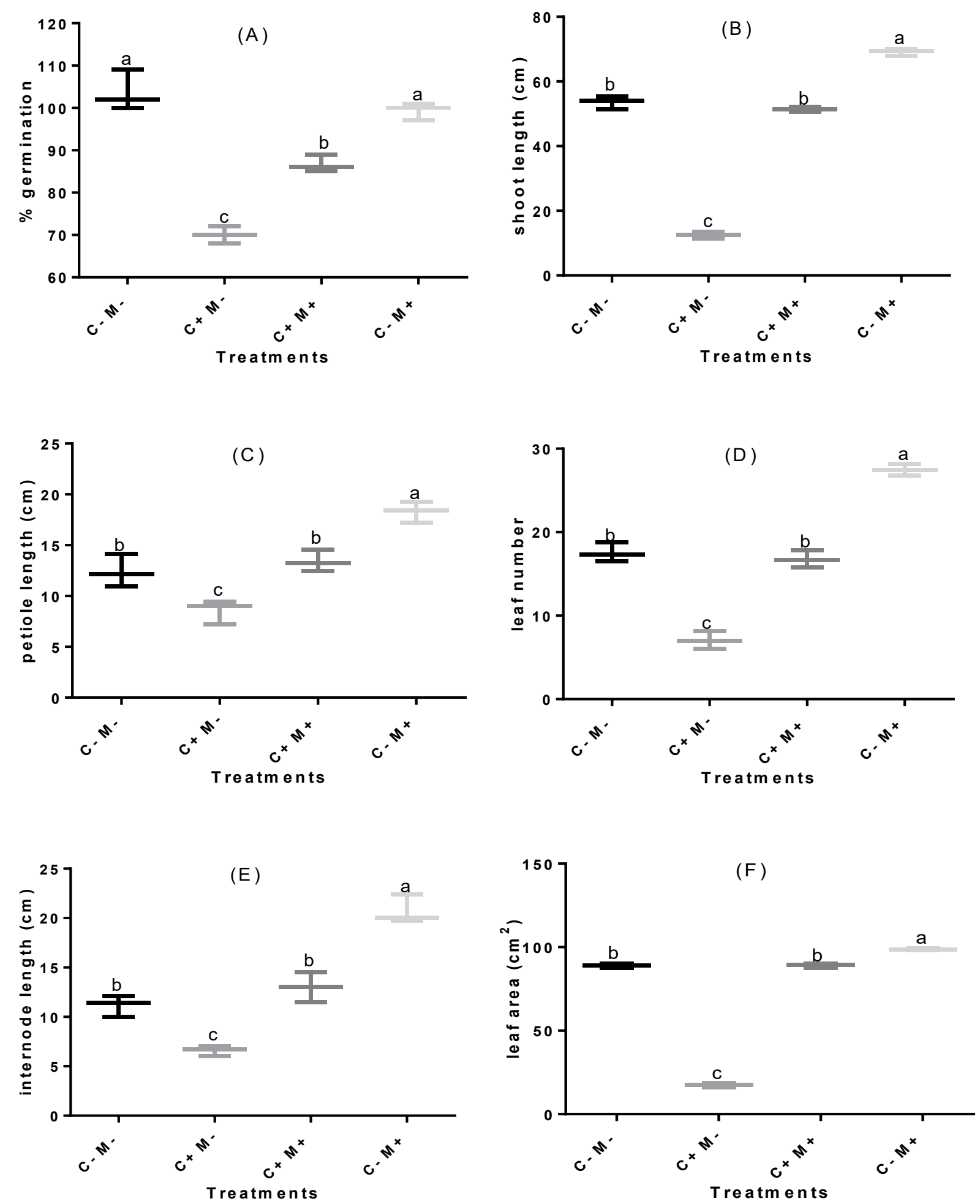

Figure 1. Effect of crude oil pollution and mycorrhizal (R. irregularis) inoculation on (A) percentage germination (B) shoot length (C) petiole length (D) leaf number (E) internode length and (F) leaf area of C. maxima

The shoot length, petiole length, number of nodes, leaf area and percentage germination of $C$. maxima were drastically $(\mathrm{p}=0.05)$ reduced in uninoculated crude oil polluted treatment $(\mathrm{C}+\mathrm{M}-)_{\text {, }}$ unpolluted mycorrhizal inoculated treatments $(\mathrm{C}-\mathrm{M}+)$ showed remarkable response in growth parameters above the control $(\mathrm{C}-\mathrm{M}-)$, while the polluted and inoculated treatment $(\mathrm{C}+\mathrm{M}+)$ showed noteworthy $(\mathrm{p}=0.05)$ increase in growth parameters when compared to the polluted uninoculated treatment $(\mathrm{C}+\mathrm{M}-)$. The results agree with the work of Ekpo et al. [22] who reported reduction in 
shoot length and general growth of soybean (Glycine max) as a result of unsatisfactory soil conditions associated with reduction in pore spaces thus increasing the demand of oxygen by hydrocarbonoclastic microorganisms. Olusola and Anslem [23] also observed reduction in general growth parameters in Amaranthus hybridus cultivated on crude oil polluted soil. Results of this research revealed that inoculation of $C$. maxima with $R$. irregularis showed more prolific growth than uninoculated treatments despite soil pollution by crude oil. Similar researches are in line with the observations of this research eg, Zea mays [24-26], Lycopesicum esculentus [27] and Amaranthus hybridus [23]. These results clearly show that crude oil contamination can hinder the growth and metabolic activities of plants, however, inoculation with AM fungi accelerates the biodegradation of several organic chemicals like; polycyclic aromatic hydrocarbons (PAHs) which are constituents of crude oil, thereby releasing functional mineral nutrients resulting to an improved in the growth and metabolism of plants [3].

Heavy metals analysis reveals a significant $(p=0.05)$ difference in the heavy metal accumulation of the C. maxima (Fig. 2). The heavy metals analyzed in this study are present thus in C. maxima; $\mathrm{Zn}>\mathrm{Cu}>\mathrm{Cr}>\mathrm{Pb}>\mathrm{Cd}$ (Fig. 2). Crude oil polluted uninoculated treatment (C+ M-) recorded the highest concentrations of heavy metals than the oil polluted inoculated (R. irregularis) treatment $(\mathrm{C}+\mathrm{M}+)$. Mycorrhizal inoculated unpolluted treatment $(\mathrm{C}-\mathrm{M}+)$ and unpolluted uninoculated treatment (C- M-) indicated the lowest heavy metal concentration (Fig. 2). This is in line with the work of Okon [28] who reported huge amount of heavy metals accumulation in Cucurbita maxima such as Zinc, cadmium, copper and chromium with increased crude oil pollution levels, with zinc showing the highest concentration. This observation agrees with the findings of Agbogidi et al. [29] who reported the accumulation of iron, zinc, cadmium, manganese, lead and cadmium contents in maize (Zea mays L.) cultivated in soil polluted with crude oil which led to poor growth and yield reduction. Lead and cadmium prevents mineral uptake by either synergistic or antagonistic reactions leading to poor growth [30]. Similarly, Ogbuehi et al. [31] reported the accumulation of zinc, lead and nickel on seeds and leaves of groundnut (Arachis hypogea) cultivated on spent engine oil polluted soil. Also, Ogbuehi et al. [32] Ogbuehi et al. [33] and Dushenkove et al. [34] reported separately that certain plants including cassava can extract heavy metals from crude oil polluted soils. Ekundayo et al. [35] in their study on the effect of spillage of crude oil on the growth, yield and nutrient assimilation of Zea mays, showed that soils contaminated with crude oil delayed germination and general growth of plants. Chukwuemeka et al. [36] reported the accumulation of Nickel, Vanadium, Cadmium, Lead, Manganese, Iron, Cobalt and Zinc in Telfairia occidentalis. Osu et al. [37] corroborates this fact by stating that Vernonia amydalin, Telfairia occidentalis and Amaranthus are good accumulators of heavy metals. Heavy metals that are found in arable crops, have a latent danger to man via the dietary pathway [38]. 

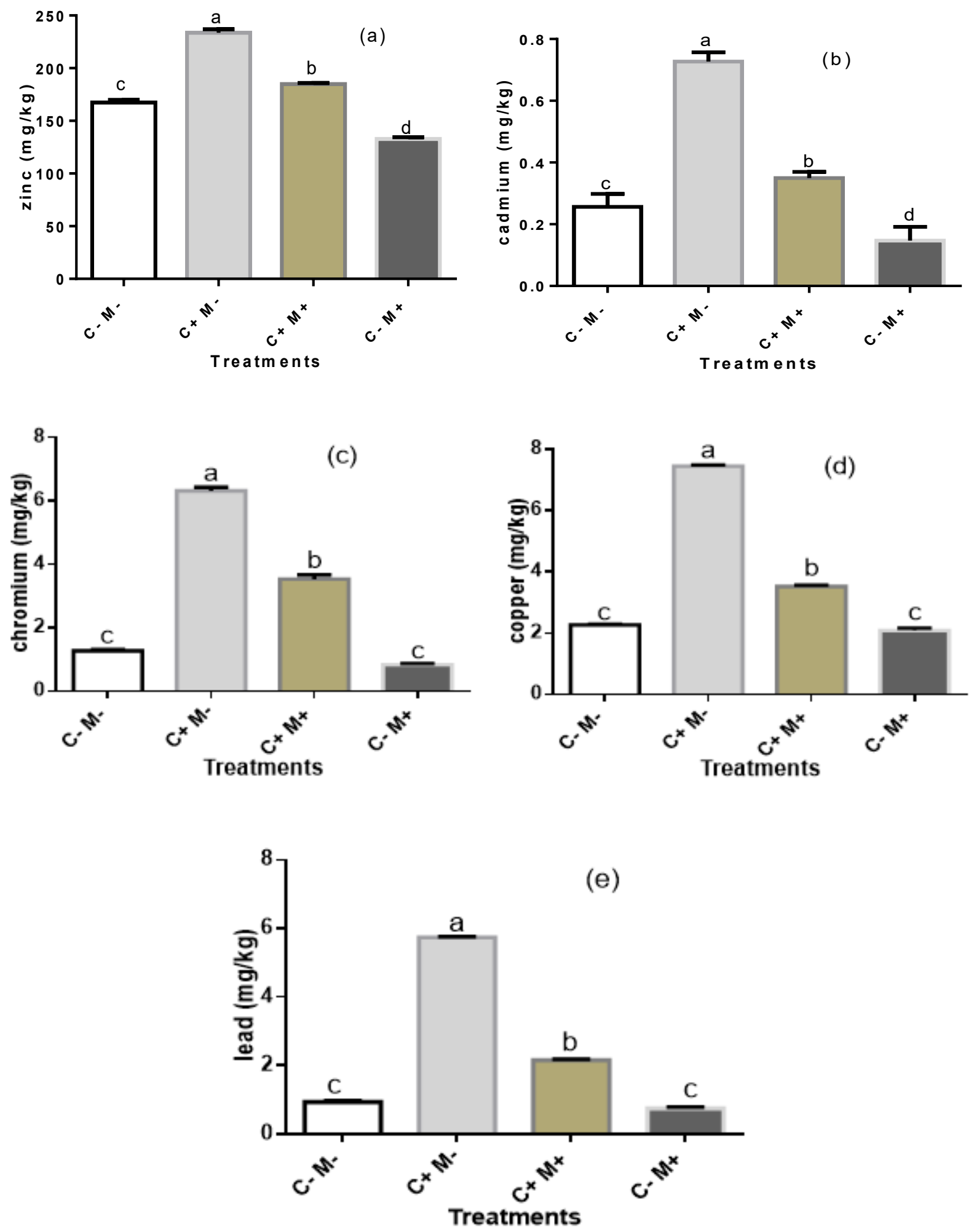

Figure 2. Effect of crude oil pollution and mycorrhizal (R. irregularis) inoculation on (a) zinc (b) cadmium (c) chromium (d) copper (e) lead concentration of C. maxima

Inoculation with $R$. irregularis significantly $(\mathrm{p}=0.05)$ reduced heavy metals uptake by $C$. maxima as observed by this study. The exclusion of $\mathrm{Pb}$ in tissues of $C$. maxima in this research is corroborated by the work of Liasu et al. [39] who reported that AMF inoculation led to Pb exclusion in Zea mays. Schneider et al. [40] also investigated the role of mycorrhizal fungi on plant diversity and bioremediation in areas polluted with $\mathrm{Pb}$ observed a noticeable reduction in $\mathrm{Pb}$ uptake hence, subsequently recommending the use of the fungi for bioremediation techniques such as biostabilization. Similarly, Hristozkova et al. [41] studied the effects of mycorrhization on the 
removal of $\mathrm{Cd}$ and $\mathrm{Pb}$ from a contaminated soil; the authors examined the effects of mycorrhizal fungi on the oil composition of Origanum majorana, as well as the antioxidant activity and the uptake and buildup of heavy metals by plants; they reported decreased uptake of $\mathrm{Cd}$ and $\mathrm{Pb}$. Galli et al. [42] reported reduction differences in $\mathrm{Cu}$ uptake among mycorrhizal and non-mycorrhizal Zea mays. Abdul et al. [3] reported that AM fungi protect Zea mays from Cu-toxicity, Therefore, corroborating the results of this study.

Abd-Allah et al. [43] reported that Cd stress adversely affected plant growth, the chlorophyll content, and the stability of the cellular membrane. Similarly, Cabral et al. [44] reported that mycorrhizal fungi inoculation resulted in fewer uptakes of $\mathrm{Cd}$ and $\mathrm{Pb}$. However, the fungi were capable to assuage the stress by positively affecting the parameters earlier mentioned. Gianinazzi et al. [45] reported that Glomus sp. decreased Cd concentrations in clover shoots and also did have impact on plant growth. Cd elimination particularly in the unpolluted treatments is possibly bridged by AM inoculation via a network of fungal hyphae that adsorb the metal and keep it sequestered on active sites of the hyphal wall [46]. Wu et al. [47] also investigated the effects of AM fungi on the exclusion of $\mathrm{Cr}$ from a polluted soil resulting in the significant immobilization of $\mathrm{Cr}$ and its subsequent reduction. Likewise, Kanwal et al. [48] studied the effects of mycorrhization on the growth of wheat plants in contaminated soil, different plant parameters including plant growth, root colonization, the content of heavy metals; Mycorrhization significantly decreased the concentration of $\mathrm{Zn}$ in plant aerial as also observed in this study.

The efficiency of AM fungi in the removal of heavy metals from the polluted soils and plant aerial part is different, and some mycorrhizal fungi may be more efficient compared with the other types of fungal species. The allocation of the heavy metals by AM fungi to different parts of the host plant is also different as some heavy metals may concentrate in the roots and some may concentrate in plant aerial part $[49,50]$. The two most important mechanisms by which the mycorrhizal fungi are able to reduce the contamination of polluted areas are phytostabilization and phytoextraction. During the uptake of heavy metals by mycorrhizal fungal hyphae, a couple of physiological mechanisms including (1) the expression of proteins such as metallothioneins and glomalin, (2) the retention of heavy metals by fungal spores, (3) chelation/complexation of heavy metals in the cellular membrane, and (4) the molecular expression of the genes results in the activation of the phytostabilization process [51].

Heavy metals (HM) frequently build up in the top soil, therefore, are available for uptake by plants via roots, which is a major entry point of HM that ultimately affects different physiological processes [52]. Cd is very toxic even at very low concentrations and do not have any known bioimportance in the biochemistry and physiology of humans [53], and long term exposure results in fragile bones and decreased bone strength [54], renal dysfunction, characterized by tubular proteinuria [55] in humans, severe irritation of the stomach leading to vomiting and diarrhea which can sometime result in death, kidney damage [54]. Cadmium is also a proven human carcinogen [54]. Thus, households or individuals that have been making uses of vegetables from the crude oil polluted sites may have predisposed themselves to serious risk of cadmium uptake, bioaccumulation and biomagnification.

The negative effect of crude oil on AMF root colonization of C. maxima by $R$. irregularis was observed in polluted and inoculated treatment (Fig. 3). Prior studies indicates that environmental stressors such as; temperature, soil moisture, $\mathrm{pH}$, tilling, root exudates and inorganic/organic contaminants (eg. Petroleum hydrocarbons)[57]. In this regard, diverse researchers have investigated extensively and reports that petroleum hydrocarbons have a detrimental effects on AMF fungal structures [57]; in Cichorium intybus there was severe decrease in percentage hyphae with increase of concentrations of $35,70,140$, and $280 \mu \mathrm{M}$ of benzo(a)pyrene [58]; in Allium porrum there was drastically lower hyphae number, and arbuscule structure of Gigaspora rosea was observed in the at $200 \mu \mathrm{l}$ of ethylbenzene [59]. The reduction in root colonization of $C$. maxima by $R$. irregularis observed in this study could be as a result of drastic reduction of moisture and oxygen amidst aggregates of soils and roots, it could also be aligned [60] to the fact that the root cortical cells under any environmental stress contains petite amounts of sugar on which AMF depends on to 
carry out its metabolic processes. The minute quantity of photosynthates is a drawback in terms of the plant ability to adapt; additionally, $30 \%$ of the carbon fixed (sugars) during photosynthesis is used by AMF [61].

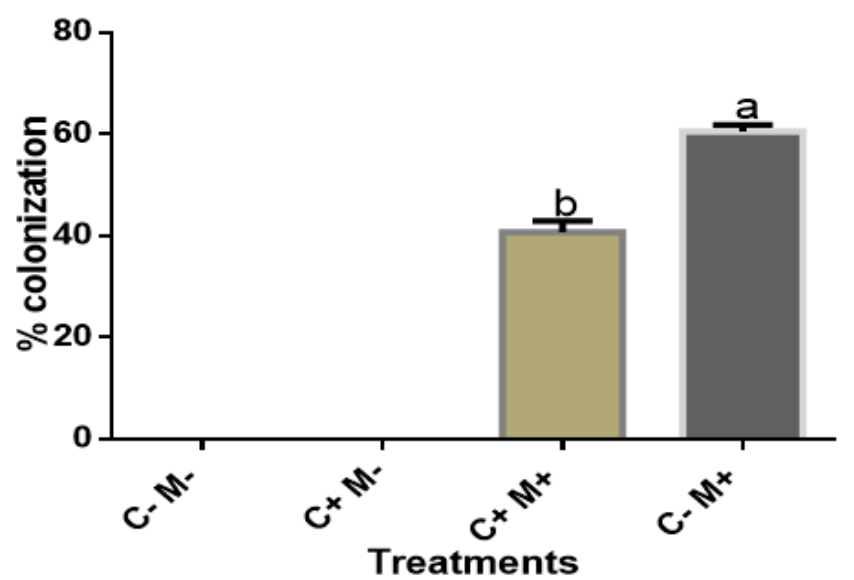

Figure 3. Mycorrhizal Colonization of C. maxima in Soil Contaminated with Crude Oil

\section{Conclusion}

Inoculation of Cucurbita maxima with AM fungus (Rhizophagus irregularis) enhanced the vegetative growth parameters both in crude oil polluted and unpolluted (control) soils. AMF inoculation inhibited the phytoextraction of heavy metals $(\mathrm{Zn}, \mathrm{Cu}, \mathrm{Cr}, \mathrm{Pb}$ and $\mathrm{Cd}$ ) from contaminated soils. Heavy metal stress, which is the result of industrialization and excess use of chemicals, is a major concern affecting large areas of the world. Although different methods have been used to mitigate the contaminated environments with heavy metals, the use of biological methods, which is the single or the combined use of plants and microbes, has been among the most effective ones. Arbuscular mycorrhizal fungi have some terrific abilities, which make them endure the stress of heavy metals and assuage the unfavorable effects of the stress on plant growth and on the environment. AM fungi can impinge on the chemical properties of heavy metals in the soil, their absorption by the host plant, and their allotment to different plant parts, affecting plant growth and the bioremediation process, thus making the AM fungi a suitable buffer for mitigating heavy metal stress on plants.

\section{Conflict of Interest}

The authors declare that there is no conflict of interest between them.

\section{References}

[1] S.S. Gill, N. Tuteja, Reactive oxygen species and antioxidant machinery in abiotic stress tolerance in crop plants, Plant Physiol. Biochem. 48 (2010) 909-930.

[2] M. Miransari, Metal tolerance in plants, in: Q.S. Wu (Ed.), Arbuscular Mycorrhizas and Stress Tolerance of Plants, Isfahan, Iran, AbtinBerkeh Scientific Ltd. Company. 2017, pp. 147-158.

[3] K.K.A. Abdul, O.L. Mojeed, J.P. Oladele, Effect of mycorrhizal inoculation on the growth and phytoextraction of heavy metals by maize grown in oil contaminated soil, Pakistani Journal of Botany. 44(1) (2012) 221-230.

[4] A. Holleman, E. Wiberg, Lehrbuch der Anorganischen Chemie, Nabu Press, Berlin, 1985.

[5] A. Jamal, N. Ayuba, M. Usmana, Arbuscular mycorrhizal fungi enhance zinc and nickel uptake from contaminated soil by soyabean and lentil. International Journal of Phytoremediation, 4 (2002) 205-221. 
[6] M. Friedlova, The influence of heavy metals on soil biological and chemical properties. Soil Water Res 5 (2010) 21-27.

[7] A. Whitmore, The emperors new clothes: sustainable mining? J. Clean Prod. 14 (2006) 309-314.

[8] A. Schübler, C. Walker, The Glomeromycota. A species list with new families and new genera. (www.amf-phylogeny.com). Accessed: 20 March 2015.

[9] S.E. Smith, D.J. Read, Mycorrhizal symbiosis ( $3^{\text {rd }}$ ed.), A San Diego: Academic, 2008.

[10] A. Franco-Ramírez et al., Arbuscular mycorrhizal fungi in chronically petroleum contaminated soils in Mexico and the effects of petroleum hydrocarbons on spore germination, Journal of Basic Microbiology. 47 (2007) 378-383.

[11] C. Nardini, L. Di Salvo, D.S.I. García, Micorrizas arbusculares: asociaciones simbióticas e indicadores de calidad ambiental en sistemas de cultivos extensivos, Revista Argentina de Microbiología. 43 (2011) 311-312.

[12] T. Pawlowska, I. Charvat, Heavy-metal stress and developmental patterns of arbuscular mycorrhizal fungi, Appl. Environ. Microbiol. 70 (2004) 6643-6649.

[13] M. Miransari, Hyperaccumulators, arbuscular mycorrhizal fungi and stress of heavy metals, Biotechnol. Adv. 29 (2011) 645-653.

[14] I.M. Villasenor, A.L.O. Bartolome, Microbiological and pharamcological studies on extracts of Cucurbita maxima, Phytotherapy research. 9(5) (1995) 376-378.

[15] F.C. Ngwerume, G.J.H. Grubben, Cucurbita maxima Duchesne. Record from PROTA4U. Grubben, G. J. H. and Denton, O. A. (Editors). PROTA (Plant Resources of Tropical Africa / Ressources végétales de l'Afrique tropicale), Wageningen, Netherlands. 2004.

[16] B.E. Okoli, Wild and cultivated cucurbits in Nigeria, Economic Botany. 38(3) (1984) 350-357.

[17] I.O. Agbagwa, B.C. Ndukwu, Cucurbita L. Species in Nigeria: under-exploited food and vegetable crops, Niger Delta Biological. 4(2) (2004) 11-15.

[18] G.J. Esenowo, N.S. Umoh, The effect of used engine oil pollution of soil on the growth and yield of Arachis hypogea L. and Zea mays L., Transactions of Nigerian Society of Biological Conservation. 5 (1996) 71-79.

[19] Association of Official Analytical Chemists (AOAC), Official Methods of Analysis. (17 ${ }^{\text {th }}$ Edn.) Arlington, Virginia: AOAC, 2003, pp. 96-105.

[20] C. Walker, A simple blue staining technique for arbuscular mycorrhizal and other rootinhibiting fungi, Inoculum. 56(4) (2005) 68-69.

[21] M. Giovannetti, B. Mosse, An evaluation of techniques for measuring vesicular arbuscular mycorrhizal infection in roots, New Phytologist. 84(3) (1980) 489-500.

[22] I.A. Ekpo et al., Effect of crude oil polluted soil on germination and growth of soybean (Glycine max), Annals of Biological Research. 3(6) (2012) 3049-3054.

[23] S.A. Olusola, E.E. Anslem, Bioremediation of a crude oil polluted soil with Pleurotus Pulmonarius and Glomus Mosseae using Amaranthus Hybridus as a test plant, Journal Bioremed. Biodegrad. 1 (2010) 113.

[24] M.O. Liasu, M.A. Azeez, M.O. Atayese, Influence of AM fungal inoculation on performance of three cultivars of maize during late seasons in a savanna soil, Science Focus. 2 (2002) 6266.

[25] J.M. Ayotamuno, R.B. Kogbara, Determining the tolerance level of Zea mays (maize) to a crude oil polluted agricultural soil, Afr. J. Biotech. 6(11) (2007). 
[26] E.M. Ogbo, A. Tabuanu, R. Ubebe, Phytotoxicity assay of diesel fuel-spiked substrates remediated with Pleurotus tuberregium using Zea mays, Int. J. Appl. Res. Natur. Prod. 3(2) (2010) 12-16.

[27] M.O. Liasu, The effect of Glomus mosseae Nicholsen Gerdmann on establishment and growth performance of transplanted potted tomato plants in soils supplemented with composted brewery waste, American-Eurasian J. Sust. Agric. 2(2) (2008) 125-134.

[28] O.G. Okon, Bioaccumulation of heavy metals in Cucurbita maxima Duch. and Telfairia occidentalis Hook. F. grown on crude oil polluted soil, American Journal of Agricultural Science. 4(4) (2017) 88-93.

[29] O.M. Agbogidi, P.G. Eruotor, S.O. Akparabi, Effects of time of application of crude oil to soil on the growth of maize (Zea mays L.), Research Journal of Environmental Toxicology. 1(3) (2007) 116-123.

[30] E. Epstein, Mineral Nutrition of plants, principles and perspective, New York, John Willey and Sons Incorporated, 1972, pp. 412-414.

[31] H.C. Ogbuehi, I.O. Ezeibekwe, M.C. Ejiogu, Impact of spent engine oil pollution on the proximate composition and accumulation of heavy metals in groundnut (Arachis hypogea) grown in Owerri, Imo State, Nigeria, Global Journal of Science. 3(12) (2011) 46-471.

[32] H.C. Ogbuehi, L.A. Akonye, Phytoextractive ability cassava cultivars to accumulate heavy metal in crude contaminated soil, International Science Research Journal. 1(1) (2008) 18-21.

[33] H.C. Ogbuehi, I.O. Ezeibekwe, U. Agbakwuru, Assessment of crude oil pollution the proximate composition and macro element of cassava crop in Owerri, Imo State, International Science Research Journal. (2) (2010) 62-65.

[34] S. Dushekove et al., Phytoremediation a novel approach to an old problem, in: Global Environment Biotechnology Proceedings of the Third Biennial Meeting of the International Society for Environmental Biotechnology 15-20. July, 1996, Boston M. A. Elsevier, New York, 1997, pp. 563.

[35] E.O. Ekundayo, T.O. Emede, D.J. Osayande, Effects of crude oil spillage on growth and yield of maize (Zea mays L.) in soil of Midwestern Nigeria, Plant Food for Human Nutrition. 56(4) (2001) 313-324.

[36] A.N. Chukwuemeka, J.U. Godwin, O.N. Alfredo, Investigation of heavy metals concentration in leaves of Telfaira occidentalis Hook. F. (Fluted Pumpkin) in Nigeria, Pol. J. Environ. Stud. 24(4) (2015) 1733-1742.

[37] C.I. Osu, E.C. Ogoko, Bioconcentration and transfer of heavy metal from soil into Verninia amydalina, Telfaira occidentalis and Amaranthus spinosus, Journal of Applied Phytotechnology in Environmental Sanitation. 3(4) (2014) 117.

[38] S. Batra, Importance of trace elements in the human body, Food and Nutrition. 5(1) (2012) 4548.

[39] M.O. Liasu, A.F. Ogundola, M.O. Atayese, Influence of mycorrhizal inoculation on growth and development of potted tomato in a soil contaminated with spent oil, Science Focus, 12(1) (2006) 59-64.

[40] J. Schneider, J. Bundschuh, C. do Nascimento, Arbuscular mycorrhizal fungi-assisted phytoremediation of a lead-contaminated site, Sci. Total Environ. 572 (2016) 86-97.

[41] M. Hristozkova et al, Aspects of mycorrhizal colonization in adaptation of sweet marjoram (Origanum majorana L.) grown on industrially polluted soil, Turk. J. Biol. 39 (2015) 461468.

[42] U. Galli, H. Schuepp, C. Brunold, Thiol of Cu-treated maize plants inoculated with the arbuscular-mycorrhizal fungus Glomus intraradices, Physiol. Plant. 94 (1995) 247-253. 
[43] E.F. Abd-Allah et al., Alleviation of adverse impact of cadmium stress in sunflower (Helianthus annuus L.) by arbuscular mycorrhizal fungi, Pak. J. Bot. 47 (2015) 785-795.

[44] L. Cabral et al., Retention of heavy metals by arbuscular mycorrhizal fungi mycelium, Química Nova. 33 (2010) 25-29.

[45] S. Gianinazzi et al., Mycorrhizal technology, in: Agriculture, Birkhăuser Nerlag, BaselBoston-Berlin, 2002.

[46] M.M. Lasat, Phytoextraction of toxic metals: A review of biological mechanisms, J. Environ. Quality. 31 (2002) 109-120.

[47] S. Wu et al., Chromium immobilization by extra-and intraradical fungal structures of arbuscular mycorrhizal symbioses, J. Haz. Mat. 316 (2016) 34-42.

[48] S. Kanwal, A. Bano, R. N. Malik, Role of arbuscular mycorrhizal fungi in phytoremediation of heavy metals and effects on growth and biochemical activities of wheat (Triticum aestivum L.) plants in Zn contaminated soils, Afr. J. Biotechnol. 15 (2016) 872-883.

[49] F. Wang, X. Lin, R. Yin, Heavy metal uptake by arbuscular mycorrhizas of Elsholtzia splendens and the potential for phytoremediation of contaminated soil, Plant Soil. 269 (2005) 225-232.

[50] F. Wang, X. Lin, R. Yin, Role of microbial inoculation and chitosan in phytoextraction of $\mathrm{Cu}$, $\mathrm{Zn}, \mathrm{Pb}$ and Cd by Elsholtzia splendens - a field case, Environ. Pollut. 147 (2007) 248-255.

[51] W. Yang et al., Metal removal from and microbial property improvement of a multiple heavy metals contaminated soil by phytoextraction with a cadmium hyperaccumulator Sedum alfredii H., J. Soils Sedim. 14 (2014) 1385-1396.

[52] N.S. Udo, O.G. Okon, Heavy metal concentrations of citrus species (Citrus reticulata and Citrus sinensis) cultivated on road sides in Uyo Metropolis in Akwa Ibom State, Nigeria, International Journal of Ecological Science and Environmental Engineering. 4(6) (2017) 8692.

[53] K. Nolan, Copper Toxicity Syndrome, The Journal of Orthomolecular Psychiatry. 12 (2003) 270-282.

[54] S. Ravichandran, Possible natural ways to eliminate toxic heavy metals, International Journal of Chem. Tech. Research. 3(4) (2011) 1886-1890.

[55] J.O. Duruibe, J.N. Ewurugwu, M.O. Ogwuegbu, Heavy metal pollution and human biotoxic effects, International Journal of Physical Science. 2 (2007) 112-118.

[56] A. Alejandro-Córdova et al., Responses of arbuscular mycorrhizal fungi and grass Leersia hexandra swartz exposed to soil with crude oil, Water Air Soil Pollut. 228 (2017) 65.

[57] Y. Gao et al., Arbuscular mycorrhizal phytoremediation of soils contaminated with phenanthrene and pyrene, Journal of Hazardous Materials. 185 (2011) 703-709.

[58] D. Debiane et al., Lipid content disturbance in the arbuscular mycorrhizal, Glomus irregulare grown in monoxenic conditions under PAHs pollution, Fungal Biology. 115 (2011) 782-792.

[59] A. Volante et al., Influence of three species of arbuscular mycorrhizal fungi on the persistence of aromatic hydrocarbons in contaminated substrates, Mycorrhiza. 16 (2005) 43-50.

[60] C.N. Brady, R.R. Weil, The nature and properties of soil, New Jersey: Pearson Prentice Hall, 2008.

[61] L. Ke et al., Fate of polycyclic aromatic hydrocarbon (PAH) contamination in a mangrove swamp in Hong Kong following an oil spill, Marine Pollution Bulletin. 45 (2002) 339-347. 